\title{
Managers' interview invitation decisions about older job applicants: human capital, economic conditions and job demands
}

\author{
JAAP OUDE MULDERS*, KÈNE HENKENS*††, YIHAO LIU§, \\ JOOP SCHIPPERS $\|$ and MO WANG§
}

\begin{abstract}
Older job applicants are vulnerable to stereotype-related bias in the recruitment process. In the current study, we examined how managers' job interview invitation decisions regarding older job applicants are influenced by applicants' human capital-related characteristics, general economic conditions and managers' perceptions of changes in organisational job demands. Data were collected in two waves of a vignette experiment, three years apart, among a sample of 211 Dutch managers from various organisations. Multi-level analysis showed that managers were more likely to invite older job applicants who had matching qualifications, were employed at the time of application and came with recommendations. In addition, managers' propensity to invite older job applicants was higher in better economic conditions. The effects of recommendations were moderated by the general economic conditions and changes in organisational job demands, such that a recommendation from another employer was especially influential in bad economic conditions, while a recommendation from an internal employee was especially influential when job demands had increased. The results emphasise the importance of considering the organisational and economic context in understanding the recruitment of older workers. The findings also suggest that older workers, employers and policy makers should invest in older workers' human capital to protect their employability.
\end{abstract}

KEY WORDS - older workers, recruitment, personnel selection, hiring, human capital, general economic conditions, job demands.

* Netherlands Interdisciplinary Demographic Institute, The Hague, The Netherlands.

$\dagger$ University Medical Center Groningen, University of Groningen, The Netherlands.

\$ Department of Sociology and Anthropology, University of Amsterdam, The Netherlands.

$\S$ Department of Management, Warrington College of Business Administration, University of Florida, Gainesville, USA.

|| Utrecht University School of Economics, Utrecht University, The Netherlands. 


\section{Introduction}

Demographic changes in recent decades, most prominently declining birth rates and increased longevity, have led to changes in the age structure of the workforce, with more older workers (aged $5^{\mathrm{O}+}$ ) than ever before (Wheaton and Crimmins 2013). In addition, due to changes in retirement legislation in many countries, older workers cannot afford to retire as early as they did in previous decades, which has resulted in increasing numbers of older workers looking for prolonged employment (D'Addio, Keese and Whitehouse 2010). However, older workers' opportunities for prolonged employment can be obstructed by their poor labour market position. For example, re-employment after job loss is negatively related to workers' age, especially after the age of $5^{\circ}$ (Wanberg et al. 2016), leading to longer unemployment durations among older workers than among younger workers (Chan and Stevens 2001). This is related to the finding that many organisations employ older workers, but do not hire them (i.e. they hire workers at younger ages and employ them into their fifties and beyond, but rarely hire older workers out of the labour market; Adler and Hilber 2009; Daniel and Heywood 2007).

One strand of the literature suggests that the poor labour market position of older workers is the result of age discrimination. Studies have shown that older workers consistently receive more negative evaluations than otherwise equivalent younger workers in different employment contexts, such as internal evaluations (Gordon, Rozelle and Baxter 1988; Rosen and Jerdee 1976) and personnel selection for hiring (Ahmed, Andersson and Hammarstedt 201 2; Bendick, Brown and Wall 1999; Perry et al. 2016). The main argument is that many employers, recruiters and managers hold predominantly negative stereotypical views of older workers and older job applicants, such as older workers having a lower willingness and ability to engage in training and to work with new technologies, and being overall less productive than younger workers (Bal et al. 2011; Finkelstein, King and Voyles 2015; Posthuma and Campion 2009; Van Dalen, Henkens and Schippers 2010), and are therefore more likely to evaluate an older worker or job applicant negatively than a younger worker or job applicant (Finkelstein, Burke and Raju 1995; Roscigno et al. 2007). However, these studies focus explicitly on age, comparing older workers to younger workers, and thereby largely ignore other factors that may influence older workers' job search outcomes. For example, it is not clear what distinguishes older workers from one another in the eyes of hiring managers. In addition, as Landy (2008) argues, many of these studies lack external validity as a result of their use of student samples and unrealistic evaluation experiments that are not generalisable to real-world situations. 
Managers' evaluation of job applications and their subsequent decision whether or not to invite a job applicant to an interview is one of the few cases that is comparable in an experimental setting and in the real world (Landy 2008). Screening job applications is one of the main methods of personnel selection that organisations use for virtually all jobs (Cole, Feild and Giles 2003; Schmidt and Zimmerman 2004). In addition, it is a phase where job applicants and managers usually have not had any personal interaction, which makes the decision prone to stereotype-related bias (Derous, Ryan and Serlie 2015; Landy 2008). Research on the effects of résumé contents on managers' hiring recommendations suggests that human capital plays an important role: résumé contents such as academic achievement and work experience are related to managers' inferences about the productivity of the job applicant and how well the job applicant may fit the job and the organisation (Chen, Huang and Lee 2011; Cole et al. 2007; Tsai et al. 2011). However, within this literature, little attention has been paid to job applicants who may suffer from stereotypical bias about their productivity, such as older job applicants, and it is therefore unclear to which extent human capital-related factors may influence employment outcomes for such groups. Studying these mechanisms for older job applicants specifically is furthermore empirically relevant in a labour market with growing proportions of older workers looking for prolonged employment. In addition, there is a need for a better understanding of boundary conditions that may alter the relationship between résumé contents and the interview invitation decision of managers (Tsai et al. 2011). In particular, economic and organisational contexts have been suggested to shape human resource management practices and micro-level decision-making among managers (Jackson and Schuler 1995; Kim and Ployhart 2014; Oude Mulders, Henkens and Schippers 2016).

Therefore, the purpose of the current study is to examine how older job applicants' human capital-related characteristics affect managers' interview invitation decisions, while also considering the effects of external economic conditions and managers' organisation-specific perception of changes in job demands. To do so, we analysed data from two waves of a vignette experiment among 211 Dutch managers from various organisations. The same experiment was carried out in 2010 (before the European debt crisis) and in 2013 (after the European debt crisis). Between the two experiments, the Dutch economy went through a persistent recession, which was part of the broader Great Recession and the European debt crisis (Organisation for Economic Co-operation and Development 2014). This is, for example, evidenced by Statistics Netherlands reporting an increase in the unemployment rate from 5.6 per cent in the second quarter of 2010 to 8.3 per cent in the second 
quarter of 2013 , while economic growth declined from 1.8 per cent (2010) to -1.2 per cent $(2013)$, and government debt increased from 59 per cent (2010) to 68.5 per cent (2013) of the gross domestic product. By studying the same decision among the same managers in these different economic conditions, we create a natural experiment that allows us to evaluate the effects of external economic conditions on how managers evaluate older job applicants. In addition, it contributes to a better understanding of the effects of recessions on human resource-related practices (Latham and Braun 2011).

\section{Theoretical framework and hypotheses}

\section{Older job applicants' human capital-related characteristics and managers' interview invitation decisions}

The screening of job applicants' résumés is often one of the first steps in the personnel selection process (Cole, Feild and Giles 2003; Schmidt and Zimmerman 2004). Because interviewing and other selection methods such as testing are costly, résumé evaluation is used as an inexpensive initial screening tool to determine whether job applicants have the characteristics that warrant further evaluation (Cole et al. 2009). The relationship between résumé contents and hiring recommendations has been well established empirically, and has been shown to be mediated by factors such as recruiters' evaluations of applicants' job competencies (Chen, Huang and Lee 2011 ; Huang, Chen and Lai 2013) and person-job and person-organisation fit (Kristof-Brown, Zimmerman and Johnson 2005; Tsai et al. 2011 ).

The human capital perspective and signalling theory can be applied to understand the relationship between job applicants' characteristics and hiring recommendations. Specifically, job applicants' characteristics, such as summarised in a résumé or, for example, learned through recommendations, generate managers' inferences about the applicants' personality (Cole et al. 2009) and work-related knowledge, skills and attributes (Chen, Huang and Lee 2011). Through these inferences, managers will form predictions about the applicant's suitability and performance for the job position, as well as the applicant's fit within the broader context of the organisation (Cole et al. 2007; Tsai et al. 2011). In other words, managers use the human capital-related characteristics of the job applicant to form evaluations about the potential productivity of the job applicant (Becker 1975). Furthermore, because the information in a résumé is limited and the predictions about a job applicant's productivity are therefore inherently uncertain, managers may draw further inferences about the job applicant based on signals that are provided in the job application 
process (Bangerter, Roulin and König 2012; Protsch and Solga 2015; Spence 1973). For example, long unemployment spells or a large number of different employers over the career of an older worker may signal an applicant's lack of loyalty or an inability to perform up to expectations (Bills 1990). Even though such inferences may be unjustified or incorrect, they matter because they influence managers' decisions whether or not to invite the job applicant for a job interview (Cole et al. 2009). Here, we specifically consider three human capital-related characteristics of older job applicants that may influence managers' interview invitation decisions: qualifications, employment status and recommendations. Note that here these mechanisms are specifically described for older job applicants, although they may work in much the same way for younger job applicants.

A job applicant's qualifications are central to the managers' inferences about the applicant. Here, we refer to qualifications in the broad sense, meaning not only formal qualifications such as diplomas and degrees, but also skills, knowledge, abilities, education and experience that may be useful for the ability to perform in a job (Erdogan et al. 2011). This is especially relevant for older job applicants, since they commonly hold fewer formal qualifications than younger job applicants, and rely more on their career track record to imply qualifications. When a manager perceives a lack of qualifications on the part of the job applicant, in other words when the job applicant is under-qualified, the manager is likely to infer a lack of person-job fit, which would lead to a lower likelihood to invite the job applicant to a job interview for further evaluation (Tsai et al. 2011). Over-qualification, in other words when the job applicant possesses qualifications that exceed job requirements (Erdogan et al. 2011), is also expected to lead to a lower likelihood of the manager to invite the job applicant for a job interview. This is because managers may find over-qualified personnel harder to motivate and fear such employees may leave when a job better suited to their qualifications becomes available (Martinez, Lengnick-Hall and Kulkarni 2014; Wald 2005).

- Hypothesis 1: Managers are less likely to invite older job applicants who are (a) over-qualified or (b) under-qualified to a job interview than those whose qualifications meet the job requirements.

As mentioned above, managers may interpret signals provided in the application to make inferences about job applicants' human capital (Bills 1990; Protsch and Solga 2015; Spence 1973). Such inferences may lead to discrimination when individuals are judged based on the generalised characteristics of the group they belong to (Akerlof 1970). One particularly important signal in this respect is the applicant's employment status (Bills 1990; Lockwood 1991). Compared to applicants that are employed 


\section{Jaap Oude Mulders et al.}

elsewhere at the time of application, unemployed applicants may be perceived by managers to be less competent and have lower human capital (Karren and Sherman 2012; Lockwood 1991). Even though the reason for unemployment may be unknown to the evaluating manager, they may consider the unemployed job applicant to possess negative attributes or characteristics that have led to unemployment. The notion that at least some unemployed individuals may have lower human capital may thereby tarnish all job applications from unemployed applicants (Akerlof 1970; Karren and Sherman 2012). This may be especially true for older job applicants in labour markets with relatively high levels of employment protection (such as in the Netherlands), since laying off employees with longer tenure is very costly so that when it happens, it may be interpreted as a reflection of the applicant's capacities (De Graaf-Zijl et al. 2015).

- Hypothesis 2: Managers are more likely to invite older job applicants who are employed elsewhere to a job interview than unemployed older job applicants.

Furthermore, managers may base their inferences of job applicants' human capital and expected productivity on recommendations from relevant sources. Letters of recommendation are regularly used in the personnel selection process, predominantly because they may include information about past performance and personality traits that may signal a good person-job fit (Muchinsky 1979). However, a common problem is that letters of recommendation include solely positive traits of job applicants, and are considered non-discriminative and non-differentiating by managers (Baxter et al. 1981 ). This may be different when the recommendation for a job applicant comes from a source that is well known by the manager and perceived as trustworthy, as these sources put their reputation at stake by making a recommendation for a specific job applicant (Marsden and Gorman 2001). In other words, a recommendation from a trustworthy source for a particular job applicant may increase the manager's perception of that applicant's suitability for the job. Two possible trustworthy sources are current employees of the organisation, who may be able to judge first-hand whether the job applicant they recommend possesses the necessary human capital for a satisfactory performance, or fellow employers or managers that the recruiting manager deems trustworthy, as they are involved in personnel selection themselves and are better able to judge applicants from an organisational perspective. For older job applicants in particular, recommendations may be especially important in the application process because person-specific recommendations have the power to challenge stereotypical images that are pervasive for older workers. 
- Hypothesis 3: Managers are more likely to invite older job applicants who are recommended by (a) a current employee of the organisation or (b) a trustworthy fellow employer to a job interview than those who do not have such recommendations.

\section{Boundary conditions of the effects of human capital-related characteristics}

The general economic conditions in which an organisation operates have wideranging implications for organisations' human resource practices and operations (Jackson and Schuler 1995; Robie et al. 2011). For example, Kim and Ployhart (2014) showed that organisations that diversified their staffing and training practices before, during and after the Great Recession were more productive and profitable in the long run. However, whether and how economic conditions such as a recession influence personnel selection processes of organisations has received little attention. Studying the effects of economic conditions on the selection of older job applicants in particular is interesting, since recessions are known to be especially tough on groups with weak labour market positions, such as older workers, although evidence also shows that the recent Great Recession affected older workers less so than earlier economic downturns (Beck 2013). Still, while older workers' tenure and steady contracts may have provided protection from layoffs, evidence shows older workers who are laid off involuntarily lose their connection to the labour market and are unlikely to find re-employment (De Graaf-Zijl et al. 2015; Neumark and Button 2014; Wanberg et al. 2016).

In the current study, we study the effects of a change in the general economic conditions on managers' selection of older job applicants in a twowave design. By comparing data from two time-points, between which the economy was in recession, we are able to investigate how the general economic conditions affect managers' evaluation of older job applicants. Specifically, we investigate both a direct effect of the general economic conditions on managers' interview invitation decision for older job applicants, and a moderation effect of the general economic conditions on the effect of older job applicants' human capital-related characteristics.

First, the general economic conditions are expected to affect directly managers' evaluations of older job applicants through a labour supply effect. In an economic recession, unemployment rises and the supply of labour increases. In other words, there will be a larger number of job applicants for the same number of job openings. There is little reason to believe that the number of job applicants invited for an interview changes as the number of job applicants change (Robie et al. 2011), which implies that when the supply of labour increases, any single job applicant is less likely 


\section{Jaap Oude Mulders et al.}

to be invited for an interview. This mechanism is especially expected to affect groups that are already disadvantaged in the labour market, such as older job applicants (De Graaf-Zijl et al. 2015; Van Dalen and Henkens 2013). Conversely, when economic conditions are comparatively better, there will be fewer job applicants, and job applicants are more likely to be invited for an interview.

- Hypothesis 4: Managers are more likely to invite older job applicants to a job interview when the general economic conditions are better than when they are worse.

Further, we expect a moderation effect of the general economic conditions on the effects of human capital-related characteristics on managers' interview decisions for older job applicants for two reasons. First, a recession often implies a large negative shock to organisations' business environments and a thorough reconsideration of organisational practices and policies (Van Dalen and Henkens 2013). In such conditions, organisations often expect that their available resources will be undermined due to the deteriorating business environment, and thus are likely to enter a mode of resource conservation (Barker and Mone 1998). When this resource conservation-oriented practice is carried out in the hiring process, it is conceivable that the managers will carefully scrutinise the candidates' human capital-related characteristics to ensure the hiring to result in favourable return on investment.

Second, a job opening is likely to attract more applicants during a recession than during better economic conditions, because of increased labour supply. Therefore, during a recession, there will be more job applicants that possess the desired human capital-related characteristics, such as the right qualifications, relevant job history and recommendations from trustworthy sources (Robie et al. 2011). As such, managers are less likely to invite job applicants who lack such characteristics for interviews. In other words, when there is a sufficient supply of qualified job applicants, managers can afford to be more selective, and job applicants that lack desirable human capital-related characteristics will be even less likely than normal to be invited for a job interview.

- Hypothesis 5: General economic conditions will moderate the effect of older job applicants' qualifications on managers' likelihood of inviting job applicants to job interviews, such that the negative effects of (a) over-qualification and (b) under-qualification will be stronger in worse general economic conditions.

- Hypothesis 6: General economic conditions will moderate the effect of older job applicants' employment status on managers' likelihood of 
inviting job applicants to job interviews, such that the positive effect of job applicants' employment status will be stronger in worse general economic conditions.

- Hypothesis 7: General economic conditions will moderate the effect of older job applicants' recommendation status on managers' likelihood of inviting job applicants to job interviews, such that the positive effects of having a recommendation from (a) a current employee and (b) a trustworthy fellow employer will be stronger in worse general economic conditions.

Next to factors external to the organisation, it is important to also consider how within-organisation developments over time affect human resource practices and managers' evaluations of older job applicants. Although many within-organisation developments may affect managers' hiring behaviour, here we focus on one interesting variable: managers' perception of changes in organisational job demands. Job demands are defined as the amount of physical or psychological effort that is required by the job (Demerouti et al. 2001; Schaufeli, Bakker and Van Rhenen 2009). Here, we focus explicitly on how managers perceive that job demands within the organisation as a whole have changed over time. Measuring changes in organisational job demands by studying managers' perceptions of them is deemed more appropriate than attempting to measure objective changes in job demands or considering employees' perceptions, since managers are most likely to draw on their own perceptions in analysing organisational needs and making hiring evaluations (Morgeson and Campion 1997). Changes in organisational job demands may specifically affect older job applicants, since older workers are commonly seen as less adaptable to changes than younger workers (Chiu et al. 2001), even though empirical research shows that older workers are not more but less resistant to changes than younger workers (Kunze, Boehm and Bruch 2013).

Since changes in organisational job demands are unlikely to affect the number of job applicants that respond to a job opening, or how many job applicants will be invited for a job interview, we do not expect a main effect of the managers' perception of changes in organisational job demands on their evaluation of older job applicants. However, we do expect that when managers have perceived a change in organisational job demands, the importance of other criteria by which they evaluate an older job applicant may change. According to the human capital perspective, workers with higher levels of human capital are better able to deal with high job demands, and are therefore less likely to experience work stress in response to high job demands than workers with lower levels of human capital (Cole et al. 2007; Schaufeli, Bakker and Van Rhenen 


\section{Jaap Oude Mulders et al.}

2009). As such, from a person-environment fit perspective (Kristof-Brown, Zimmerman and Johnson 2005), managers may expect older job applicants with higher levels of human capital to have better person-job fit when they have perceived an increase in organisational job demands. Since the human capital of job applicants is inferred from characteristics such as qualifications, employment status and relevant recommendations (Chen, Huang and Lee 2011; Tsai et al. 2011), we expect that managers will value these characteristics more in their evaluation of job applicants when they have perceived an increase in job demands than when they have not.

- Hypothesis 8: Managers' perception of changes in organisational job demands will moderate the effect of job applicants' qualifications on managers' likelihood of inviting older job applicants to job interviews, such that the negative effects of (a) over-qualification and (b) under-qualification will be stronger for managers who have perceived an increase (versus a decrease) in job demands.

- Hypothesis 9: Managers' perception of changes in organisational job demands will moderate the effect of job applicants' employment status on managers' likelihood of inviting older job applicants to job interviews, such that the positive effect of job applicants' employment status will be stronger for managers who have perceived an increase (versus a decrease) in job demands.

- Hypothesis 10: Managers' perception of changes in organisational job demands will moderate the effect of job applicants' recommendation status on managers' likelihood of inviting older job applicants to job interviews, such that the positive effects of having a recommendation from (a) a current employee and (b) a trustworthy fellow employer will be stronger for managers who have perceived an increase (versus a decrease) in job demands.

\section{Methods}

\section{Sample and procedure}

Two waves of a vignette experiment (also known as a factorial survey; Rossi and Anderson 1982; Wallander 2009) were conducted in 2010 and 2013 with a sample of managers from the Longitudinal Internet Studies for the Social Sciences (LISS) panel of CentERdata, Tilburg University, The Netherlands. The vignette experiments were embedded in broader questionnaires about managers' images of younger and older workers, and participants were not informed of the specific purpose of the vignette experiments. The LISS panel consists of a representative sample of Dutch 
inhabitants who participate in monthly internet surveys on a variety of topics (Scherpenzeel and Das 2010; for more information, see http://www.lissdata. $\mathrm{nl})$. For the current study, we randomly selected a sample of 700 managers who had indicated that they worked in a management position and were responsible for recruitment, selection and hiring of employees in their organisation; 426 out of the 700 approached managers responded in the first wave of the study in May 2010, for a response rate of 60.9 per cent. Shortly before the second wave of the vignette experiment, participants were asked to complete a brief questionnaire on changes in their organisation since the first experiment. This questionnaire was separated from the second wave of the vignette experiment to limit the risk of carryover effects (Tourangeau et al. 1989). Of the 426 initial respondents, 275 participated in the second wave of the vignette experiment in April 2013, implying a retention rate of 64.6 per cent. Managers who changed jobs, had become unemployed or had retired between the two waves of the vignette experiment $(\mathrm{N}=64)$ were excluded from the analysis, rendering a final sample size of 211 . The average age of the managers was 48.35 years (standard deviation $(\mathrm{SD})=9.44)$ at the time of the second vignette experiment. The majority of managers in the sample were male $(70.1 \%)$; and 23.2 per cent of the managers worked in the industry and construction sector, 22.8 per cent in the services and trade sector, 25.6 per cent in the public sector and 28.4 per cent in other non-specified sectors. ${ }^{1}$

A vignette experiment combines survey questions with experimental methods, and is considered especially suitable for uncovering the underlying structure of human judgements in social contexts (Rossi and Anderson 1982; Wallander 2009). Participants in this type of experiment usually see a vignette that contains descriptive information about the situation, after which they are prompted for their judgement. In the current study, the vignettes contained variables on three human capital-related characteristics of the older job applicant (qualifications, employment status and recommendation) and two control variables (applicant's age and gender). The values on these vignette factors are randomised, so that each combination of values is equally likely (an example of a random vignette is presented in Figure 1). Because of this, the vignette factors are independent of each other and their effects can be reliably estimated (Wallander 2009). It is common to have participants complete multiple vignettes, in order to increase the reliability of the estimates and to be able to assess both between-subject and within-subject effects (Wallander 2009). In the current study, participants completed five vignettes in each wave, so there were ten observations for each participant. Our final sample thus consisted of 2,110 vignette observations from 211 participants, evenly split over the two waves. 


\section{$85^{\circ}$ Jaap Oude Mulders et al.}

Consider a situation where your organisation is looking for new employees. You will be shown key characteristics of several job applicants. Please indicate, for each applicant, the likelihood that you would select this person for a job interview.

\begin{tabular}{|ll|}
\hline Age & 54 years \\
Gender & Female \\
Qualifications & Under-qualified \\
Employment status & Still employed elsewhere \\
Recommendation & From one of your current employees \\
\hline
\end{tabular}

What is the likelihood that you would select this person for a job interview?

\begin{tabular}{|c|c|c|c|c|c|c|c|c|c|}
\hline 2 & 3 & 4 & 5 & 6 & 7 & 8 & 9 & 10 & 11 \\
\hline Very unlikely & & & & Neutr & & & & \multicolumn{2}{|c|}{ Very likely } \\
\hline
\end{tabular}

Figure 1. Example of a vignette.

\section{Measures}

Qualifications. Job applicants' qualifications were manipulated. Applicants were described in the vignettes as 'under-qualified', 'qualified' or 'overqualified'. We used the 'qualified' category as the reference category in the analysis for this variable.

Employment status. Job applicants' employment status was manipulated. Applicants were described in the vignettes as either 'employed elsewhere' or 'unemployed'. We used the 'unemployed' category as the reference category in the analysis for this variable.

Recommendation. Job applicants' recommendations were manipulated. Applicants were described in the vignettes as 'recommended by a current employee', 'recommended by a trustworthy fellow employer' or had 'no recommendations'. We used the 'no recommendations' category as the reference category in the analysis for this variable.

General economic conditions. The general economic conditions were assessed with a dummy for the year in which the experiment took place. Observations under relatively worse general economic conditions (April 2013) were coded o; observations from relatively better general economic conditions (May 2010) were coded 1.

Managers' perception of changes in organisational job demands. In the questionnaire conducted two months before the second wave of the vignette experiment, managers' perception of changes in organisational job 
demands was assessed with a single question that read 'In the last three years, how did job demands change in your organisation?' The answers were recorded on a five-point scale ( 1 = 'strongly decreased', 3 = 'remained the same', 5 = 'strongly increased').

Interview invitation decision. The managers' decision whether or not to invite a job applicant for an interview was measured on a scale from 1 ('very unlikely') to 11 ('very likely').

Control variables. Job applicants' age was manipulated and appeared on the

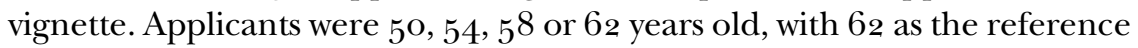
category in the analysis. Job applicants' gender was also manipulated in the vignette, with female as the reference category in the analysis.

\section{Analytic strategy}

The data had a nested structure, with responses to ten vignettes nested within each participant. Therefore, we performed multi-level modelling to account for this data structure in Mplus 7 software. Specifically, a twolevel model was specified. At Level 1 (i.e. the within-individual level), we created a dummy variable for year to distinguish between vignettes from the two different general economic conditions (i.e. $\mathrm{o}={ }^{\prime} 2013$ ' and $1=$ '2010') and five other sets of dummy variables for applicants' qualifications, employment status, recommendation, age and gender. The interaction terms between general economic conditions and applicants' human capital-related characteristics were created by multiplying the dummy variables accordingly. We then specified the random effects (i.e. random slopes) of each vignette-based dummy variable, the fixed effect of the dummy variable of general economic conditions, as well as the fixed effects of general economic conditions by human capital characteristic interaction terms on likelihood of job interview. At Level 2 (i.e. the between-individual level), we specified the fixed effects of managers' perception of changes in organisational job demands (grand-mean centred before analysis) on likelihood of job interview and on the random slopes we specified at Level 1.

\section{Results}

Preliminary analysis

Means, standard deviations and correlations of the non-manipulated study variables are presented in Table 1 . Overall, participants were on average 
T А в LE 1. Means, standard deviations (SD) and correlations of nonmanipulated study variables

\begin{tabular}{|c|c|c|c|c|c|c|c|}
\hline Variable & Mean & $\begin{array}{l}\text { Within- } \\
\text { person } \\
\text { SD }\end{array}$ & $\begin{array}{l}\text { Between- } \\
\text { person SD }\end{array}$ & 1 & 2 & 3 & 4 \\
\hline 1. Respondent's age & $4^{8.4}$ & & $9 \cdot 4$ & & & & 0.04 \\
\hline 2. Respondent's gender & 0.3 & & 0.5 & -0.03 & & & -0.01 \\
\hline $\begin{array}{l}\text { 3. Change in job } \\
\text { demands }\end{array}$ & 3.8 & & 0.9 & 0.07 & 0.11 & & -0.03 \\
\hline $\begin{array}{l}\text { 4. Likelihood of select- } \\
\text { ing applicant for job } \\
\text { interview }\end{array}$ & $5 \cdot 3$ & 2.4 & 1.6 & 0.06 & -0.02 & -0.04 & \\
\hline
\end{tabular}

Notes: The vignette characteristics were random, so they are not significantly correlated with each other or other variables. Correlations below the diagonal represent between-subject correlations $(N=211)$. To calculate the between-subject correlation for the dependent variable (i.e. likelihood of selecting applicant for job interview) we averaged the within-subject scores. The respondent's gender was scored o for men and 1 for women. Correlations above the diagonal represent within-subject correlations $(N=2,110)$.

slightly unlikely to invite older job applicants to an interview (mean $=5 \cdot 33$, within-person $\mathrm{SD}=2.41$, between-person $\mathrm{SD}=1.5^{8}$ ). One-way randomfactor analysis of variance results showed that the between-person variances were significant for the dependent variable, intraclass correlation coefficient $=0.35, F(210,1,899)=6.43, p<0.01$, warranting the use of multilevel modelling for analysing the current data. Further, the average score of managers' perception of changes in organisational job demands $($ mean $=3.82, \mathrm{SD}=0.87)$ indicates that, on average, managers perceived an increase in job demands in their organisations between 2010 and 2013.

\section{Hypothesis testing}

Unstandardised coefficient estimates for the model are presented in Table 2. Model 1 presents a baseline model which only contains Level 1 main effects of older job applicants' characteristics and the general economic conditions on managers' likelihood of inviting older job applicants for interview. Applicant's qualifications were related to managers' interview invitation decisions in the expected direction. Managers were less likely to invite older job applicants that were either under-qualified $\left(\gamma=-1.5^{8}\right.$, $p<0.01)$ or over-qualified $(\gamma=-0.24, p<0.05)$ than those that had qualifications fitting the job description, supporting Hypothesis 1. Further, managers were more likely to invite older job applicants that were employed elsewhere than applicants that were unemployed $(\gamma=0.39, p<0.01)$, providing support for Hypothesis 2. Managers were also more likely to invite older job applicants with a recommendation from a current employee of 
T A B L E 2. Unstandardised coefficients of the multi-level model

\begin{tabular}{|c|c|c|c|c|c|c|}
\hline \multirow[b]{3}{*}{ Variable } & \multicolumn{6}{|c|}{$\begin{array}{c}\text { Likelihood of selecting applicant for job } \\
\text { interview }\end{array}$} \\
\hline & \multicolumn{3}{|c|}{ Model 1} & \multicolumn{3}{|c|}{ Model 2} \\
\hline & Estimate & $p$ & $\mathrm{SE}$ & Estimate & $p$ & $\mathrm{SE}$ \\
\hline \multicolumn{7}{|l|}{ Fixed effects: } \\
\hline Intercept & 5.08 & $* * *$ & 0.17 & 4.95 & **** & 0.20 \\
\hline Applicant under-qualified (Ref. Qualified) & $-1.5^{8}$ & $* * *$ & 0.13 & $-1.4^{2}$ & $* * *$ & 0.17 \\
\hline Applicant over-qualified (Ref. Qualified) & -0.24 & * & 0.11 & -0.13 & & 0.15 \\
\hline $\begin{array}{l}\text { Applicant employed elsewhere } \\
\text { (Ref. Unemployed) }\end{array}$ & 0.39 & $* * *$ & 0.09 & $0.3^{6}$ & $* *$ & 0.12 \\
\hline $\begin{array}{l}\text { Applicant recommendation from } \\
\text { employee (Ref. No recommendation) }\end{array}$ & 0.34 & $* *$ & 0.11 & $0.4^{2}$ & ** & 0.15 \\
\hline $\begin{array}{l}\text { Applicant recommendation from employer } \\
\text { (Ref. No recommendation) }\end{array}$ & 0.33 & $* *$ & 0.10 & $0.5^{6}$ & $* * *$ & 0.13 \\
\hline Applicant age $5^{\circ}$ years (Ref. 62 years) & 0.64 & $* * *$ & 0.12 & 0.66 & ** & 0.20 \\
\hline Applicant age 54 years (Ref. 62 years) & 0.55 & $* * *$ & 0.12 & 0.62 & **** & 0.17 \\
\hline Applicant age $5^{8}$ years (Ref. 62 years) & 0.18 & & 0.10 & 0.05 & & 0.16 \\
\hline Applicant male (Ref. Female) & -0.09 & & 0.08 & -0.16 & & 0.11 \\
\hline GEC & 0.55 & $* * *$ & 0.15 & 0.85 & ** & 0.29 \\
\hline COJD & & & & -0.16 & & 0.20 \\
\hline GEC $\times$ Under-qualified & & & & -0.31 & & 0.21 \\
\hline GEC $\times$ Over-qualified & & & & -0.25 & & 0.21 \\
\hline GEC $\times$ Employed elsewhere & & & & 0.06 & & 0.17 \\
\hline GEC $\times$ Recommendation from employee & & & & -0.20 & & 0.20 \\
\hline GEC $\times$ Recommendation from employer & & & & $-0.5^{1}$ & ** & 0.19 \\
\hline GEC $\times$ Age $5^{\circ}$ years & & & & -0.02 & & 0.26 \\
\hline GEC $\times$ Age 54 years & & & & -0.18 & & 0.23 \\
\hline GEC $\times$ Age $5^{8}$ years & & & & 0.24 & & 0.21 \\
\hline GEC $\times$ Male & & & & 0.15 & & 0.16 \\
\hline COJD $\times$ Under-qualified & & & & -0.24 & & 0.15 \\
\hline COJD $\times$ Over-qualified & & & & 0.04 & & 0.13 \\
\hline COJD $\times$ Employed elsewhere & & & & 0.05 & & 0.10 \\
\hline COJD $\times$ Recommendation from employee & & & & $0.3^{8}$ & ** & 0.12 \\
\hline COJD $\times$ Recommendation from employer & & & & 0.14 & & 0.12 \\
\hline COJD $\times$ Age 50 years & & & & 0.21 & & 0.13 \\
\hline COJD $\times$ Age 54 years & & & & -0.13 & & 0.13 \\
\hline COJD $\times$ Age $5^{8}$ years & & & & -0.08 & & 0.11 \\
\hline COJD $\times$ Male & & & & -0.06 & & 0.08 \\
\hline \multicolumn{7}{|l|}{ Variance components: } \\
\hline Level 1 residual variance & $2.5^{1}$ & $* * *$ & 0.20 & 2.47 & $* * *$ & 0.20 \\
\hline Level 2 residual variance & 2.03 & $* * *$ & 0.27 & 1.94 & **** & 0.27 \\
\hline
\end{tabular}

Notes: SE: standard error. Ref.: reference category. GEC: general economic conditions. COJD: changes in organisational job demands.

Significance levels: $* p<0.05, * * p<0.01, * * * p<0.001$.

the organisation $(\gamma=0.34, p<0.01)$ or from a fellow employer $(\gamma=0.33, p<$ o.o1) than those with no recommendation, supporting Hypothesis 3 . These results indicate that, as expected, older job applicants' human capitalrelated characteristics are very important factors affecting managers' 


\section{Jaap Oude Mulders et al.}

decisions whether or not to invite them to a job interview. Although not the focus of this study and not hypothesised, it should be noted that applicants' age also strongly affects managers' evaluations, with applicants of $5^{\mathrm{o}}$ and 54 years old being much more positively evaluated than applicants of 58 and 62 years old. Indeed, applicants' age is more important in predicting managers' evaluations than applicants' employment status or whether they have any relevant recommendations.

We also found that managers' likelihood of inviting older job applicants for a job interview was higher when general economic conditions were better (i.e. in May 2010) than when general economic conditions were worse, after several years of recession (i.e. in April 2013), $\gamma=0.55, p<$ o.o1. Hypothesis 4 is thus also supported.

In Model 2, the interaction effects between the general economic conditions and the applicants' characteristics were added, as well as the cross-level interaction effects between managers' perception of changes in organisational job demands and applicants' characteristics, and the between-individual main effect of managers' perception of changes in organisational job demands. Snijders and Bosker's (1999) formulas were used to calculate pseudo- $R^{2}$ for the effect sizes in predicting the outcome variable. All predictors included in the model accounted for 19 per cent of the total variance in managers' interview invitation decisions, suggesting the model explained a sizeable portion of the variation in the outcome variable. As presented in Table 2, the majority of the main effects of human capital-related characteristics on managers' likelihood of inviting older job applicants for interview still held significant, except for the effect of over-qualification $(\gamma=-0.13$, $p>0.05)$. Further, Model 2 shows that the interaction effects between the general economic conditions and the applicants' qualifications and employment status were not significant, providing no support for Hypotheses 5 and 6 . However, the interaction between general economic conditions and the applicant being recommended by a fellow employer was significant $\left(\gamma=-0.5^{1}, p<0.01\right)$ in predicting managers' job interview decisions. This interaction effect is illustrated in Figure 2, which shows that managers were more likely to invite older job applicants who hold a recommendation from a fellow employer than those with no recommendations when the general economic conditions were worse. This finding provides support for Hypothesis $7 \mathrm{~b}$ (but not $7 \mathrm{a}$ ).

With regard to changes in organisational job demands, Table 2 shows that the interaction effects between changes in organisational job demands and older job applicants' qualifications and employment status were not significant, providing no support for Hypotheses 8 and 9. An interaction effect is observed between changes in organisational job demands and the applicant being recommended by an employee of the organisation $\left(\gamma=0.3^{8}\right.$, 


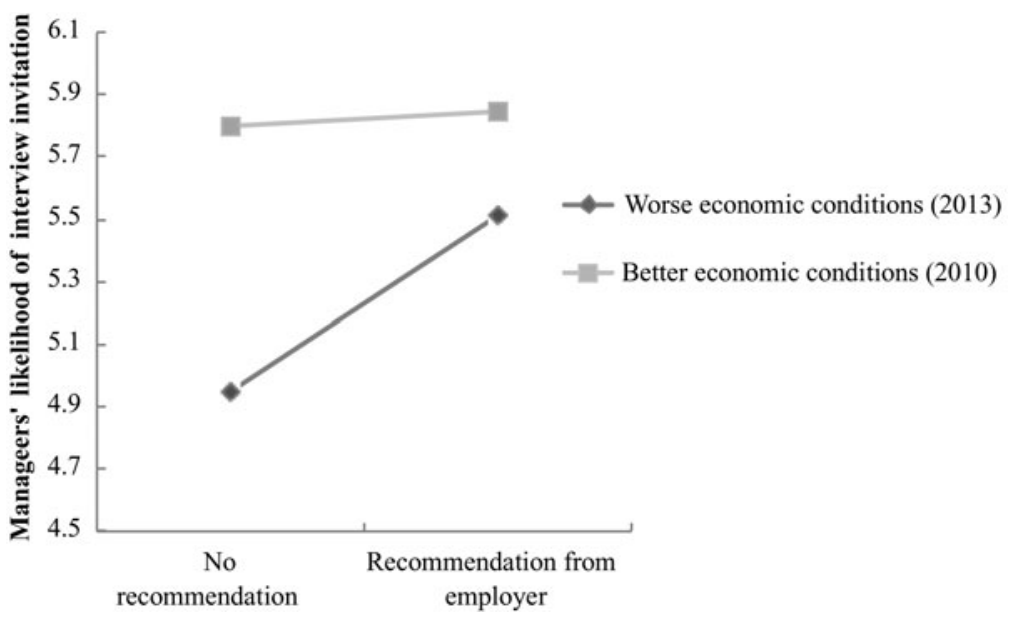

Figure 2. Illustration of the interaction effect between general economic conditions and applicants' recommendations.

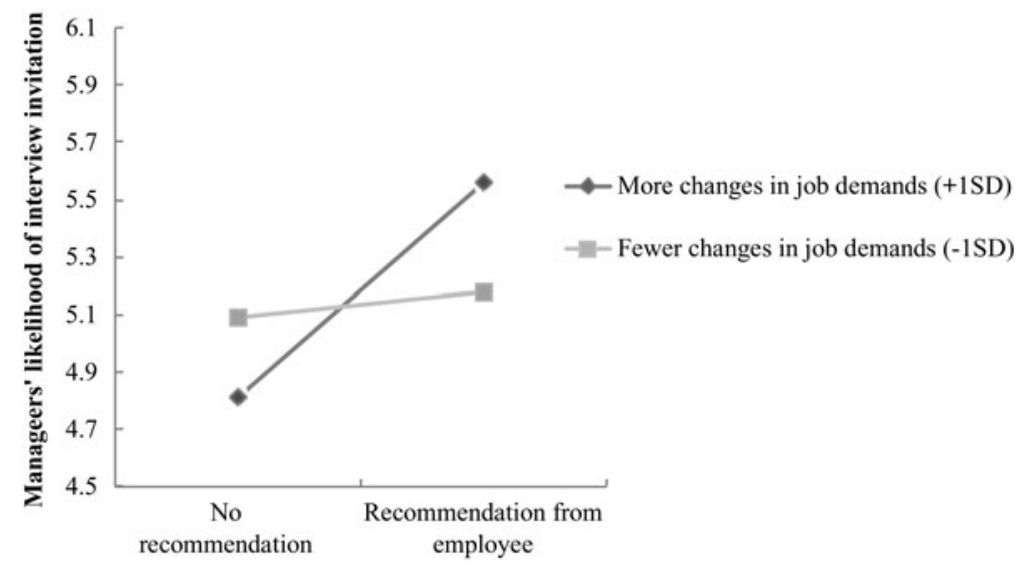

Figure 3. Illustration of the interaction effect between managers' perception of changes in organisational job demands and applicants' recommendations.

Note: SD: standard deviation.

$p<0.01)$. This interaction effect is illustrated in Figure 3, which shows that when managers had perceived an increase (versus decrease) in the level of organisational job demands in recent years, they were more likely to invite older job applicants with a recommendation from a current employee of the organisation to an interview than those with no recommendations. This provides support for Hypothesis loa (but not 1ob). 


\section{Discussion}

In the current study, we found that managers' interview invitation decisions regarding older job applicants were strongly associated with applicants' human capital-related characteristics. In particular, managers were more likely to interview older job applicants who had matching qualifications than those who were under-qualified or over-qualified, who were employed elsewhere over those who were unemployed, and who had recommendations from an employer or an employee of the organisation over those who did not have such recommendations. Also, managers were more likely to invite older job applicants to an interview in better general economic conditions than in worse general economic conditions. Further, the effects of applicants' recommendations on managers' interview invitation decisions were moderated by the general economic conditions and managers' perceptions of changes in organisational job demands, with a recommendation from a fellow employer being especially relevant in bad economic conditions, and a recommendation from an employee within the organisation being especially relevant when job demands had increased.

We did not find the hypothesised interaction effects between the other two human capital-related characteristics (i.e. applicants' qualifications and employment status) and general economic conditions and changes in organisational job demands. A possible reason might be that job applicants' qualifications and employment status were already very important in managers' decision-making regarding job interview invitations, and that external conditions could not further increase their importance. Regardless of economic and organisational contexts, the effects of these human capitalrelated characteristics appear to be quite robust.

\section{Theoretical and practical implications}

The current findings have important theoretical and practical implications. First, theoretically, our findings support the human capital mechanism that has been suggested in earlier studies (e.g. Chen, Huang and Lee 2011 ; Cole et al. 2007; Tsai et al. 2011 ), and thus shows that human capital-related characteristics are one of the most important drivers of managers' interview invitation decisions when screening older job applicants. More specifically, we found that under-qualification and over-qualification were both harmful to older job applicants' job perspectives, but that under-qualification was about six to seven times more harmful than over-qualification in terms of its predictive effect. When the economic and organisational contexts were considered, the harmful effect of over-qualification even disappeared, and over-qualified older job applicants were equally likely as those with fitting 
qualifications to be invited to a job interview. This finding suggests that overqualification may not be as detrimental for older workers as it is for younger workers, since older workers are often more motivated to support and mentor others than younger workers, while over-qualified older workers may be less likely than over-qualified younger workers to display high turnover rates and low motivation (Erdogan et al. 2011). Overall, we conclude that over-qualification may be a smaller concern for older job applicants than is sometimes assumed. Further, our results offer support for the notion that the unemployment status may manifest as a stigma that can lead to unjustified perceptions of lower human capital on the part of job applicants, which appears to be especially relevant for vulnerable groups such as older workers (Karren and Sherman 2012).

Second, our results also indicate that managers were more likely to invite older job applicants to a job interview when general economic conditions were better, and that general economic conditions and managers' perceptions of changes in organisational job demands moderated the effects of applicants' recommendations on managers' interview invitation decisions. However, the expected moderation effects between applicants' qualifications and employment status and general economic conditions and changes in organisational job demands were not found, rendering the effect of especially within-organisation changes on managers' evaluation of older job applicants rather small. Although this may be related to measurement limitations (discussed further below), this finding indicates that within-organisation developments are not as strongly related to managers' evaluations of older job applicants as we expected. Still, the findings support previous research that suggests general economic conditions affect organisations' human resource practices in various ways, which may specifically affect older workers or older job applicants (Robie et al. 2011 ; Van Dalen and Henkens 2013). In particular, the observation that unemployed older workers find it very difficult to find re-employment, especially after a recession (e.g. De Graaf-Zijl et al. 2015; Wanberg et al. 2016), can be partly explained by managers being much less likely to invite older job applicants to a job interview in worse economic conditions.

With regard to the effects of recommendations, our results showed that recommendations from a fellow employer were especially important in bad economic conditions, whereas a recommendation from an employee of the organisation was especially important when job demands had increased in recent years. This difference in the importance of employee and employer recommendations was not expected based on our theoretical reasoning, but we think this may be because managers trust other employers to be better able to judge whether a job applicant is suitable from an organisational point of view since other employers know what is called for in bad 


\section{${ }_{85}^{8}$ Jaap Oude Mulders et al.}

economic conditions. Conversely, managers may trust the judgement of current employees of their own organisation more when the manager has perceived an increase in job demands, because the recommending employee has also had to deal with those increasing job demands. An interesting direction for future research would be to investigate this particular mechanism more closely, and to study to what extent recommendations from employees and employers that are external and internal to the organisation are valued differently.

Moreover, although not the prime focus of this study, we found a negative effect of applicants' age on managers' interview invitation decision. This corroborates findings from earlier studies regarding age discrimination in hiring (Roscigno et al. 2007), and shows that even within the group of older job applicants, age negatively affects labour market success (Karpinska, Henkens and Schippers 2013; Oude Mulders et al. 2014). The results do not show any interaction effects between applicants' age and general economic conditions and changes in organisational job demands, suggesting that within the group of older job applicants, the young-old job applicants were not less negatively affected by difficult economic or organisational circumstances than old-old job applicants. This finding informs the changing legislative framework in which employers operate and supports the notion that both young-old and old-old job applicants deserve the same level of protection in the face of adverse labour market conditions (Beck 2013). Still, it should be noted that applicants' age is a strong predictor of managers' evaluations of older job applicants, and that age is more important in predicting managers' evaluations than applicants' employment status or whether they have any relevant recommendations. Even though age discrimination is explicitly prohibited in many countries, this research shows that many managers do use age as a selection criterion in their evaluation of job applicants, even when human capital-related characteristics of applicants are controlled for, and that especially job applicants aged $5^{8}$ or over are judged negatively.

Practically, on the policy level, although most developed countries have anti-age discrimination legislation in place, Neumark and Button (2014) have found that such legislation has not been particularly helpful in protecting older workers, and may sometimes even be detrimental to older workers' employment potentials. Addressing the disadvantage that older workers and job applicants may face, our findings suggest that older job applicants themselves can increase their chances of job market success by updating their qualifications during their career. Also, policy makers could try to make training more attainable for older job workers so that their qualifications are more in line with changing job requirements. Special policy measures may be needed to protect the interests of older 
job applicants in bad economic conditions, as the findings here suggest older job applicants are strongly affected in those circumstances. Organisations can also try to adjust their job design and personnel selection procedure to attach more value to older job applicants' experience and mentoring skills (Wang, Olson and Shultz 2013).

\section{Limitations and future research}

This study has several limitations. First, an inherent limitation of the vignette experiment method is that participants judge hypothetical situations, which limits the generalisability of the findings (Hainmueller, Hangartner and Yamamoto 2015; Wallander 2009). In particular, real-world selection managers or recruiters have more detailed information available about job applicants than we were able to provide in the experiment. In addition, the judgements in the experiment are without consequences for the managers and their organisations, which may imply an under-estimation of the effects of several important factors (Pager and Quillian 2005). Still, we studied the interview invitation decision in a sample of real-world managers, who in reality also judge an applicant's résumé on paper or on screen without meeting the applicant in person (Derous, Ryan and Serlie 2015; Landy 2008). It is important for future research to study both actual behaviour and improve the external validity of research by using designs that mimic real-world incentives for the participants, such as the paired conjoint design (Hainmueller, Hangartner and Yamamoto 2015).

Second, the study design limited the opportunity to examine interaction effects. This applies especially to factors manipulated at Level 1 , because a full factorial design is impossible given the amount of Level 1 variables that we studied in the current study and the small amount of vignettes that we asked the managers to evaluate. Future studies using large field samples (i.e. measuring characteristics of real job applicants) may be able to allow the evaluation of more interaction effects.

Third, we assessed changes in organisational job demands with a singleitem measure, two months before the second wave of the vignette experiment. Although the measure of changes in organisational job demands was separated from the vignette experiments to limit carryover effects, future studies could increase the validity and reliability of the measure by assessing job demands at each wave of the experiment and computing change scores, as well as by using previously established multi-item scales, such as parts of the Questionnaire on the Experience and Evaluation of Work (e.g. Schaufeli, Bakker and Van Rhenen 2009) or the Job Content Questionnaire (Karasek et al. 1998). In addition, future studies could include a measure on expected future changes in job demands, since this 
may be more directly related to outcomes for older job applicants due to the stereotype that older workers are more resistant to changes (Chiu et al. 2001; Kunze, Boehm and Bruch 2013). Next to improving the measure of organisational job demands, it is also important that future studies study the effects of other organisation-specific developments on managers' hiring behaviour and organisations' human resource practices, such as changes in the age composition of the workforce, the organisation of work in teams and whether the organisation has gone through restructuring.

Next to addressing these limitations, future research could try to expand on our findings by considering other types of personnel selection decisions and employment outcomes for older job applicants and older workers. Also, future research could address the topic of how managers' characteristics may influence their decisions, and how the combination of applicants' and managers' characteristics (such as their age (dis) similarity) may affect employment outcomes. Finally, future studies may try to replicate and expand on our findings, focusing on a different country or studying national and cultural variation in a multi-country study.

\section{Conclusion}

The current study demonstrated that managers' interview invitation decisions regarding older job applicants were strongly associated with the applicants' human capital-related characteristics, and were also affected by the general economic conditions. Furthermore, the effect of older job applicants' recommendations on managers' interview invitation decisions was moderated by the general economic conditions and the changes in organisational job demands. The findings suggest that older workers should pay attention to updating their human capital during their career, and employers and policy makers should create opportunities to facilitate that. Older job applicants also have to consider getting recommendations that come from relevant sources to improve their chances across different economic conditions and organisational contexts.

\section{Acknowledgements}

This research was supported by the Netherlands Organization for Scientific Research NWO (VICI Grant 453-14-oo1 to KH), Netspar (grant IRG2o16.o3 to JOM and $\mathrm{KH}$ ) and the Netherlands Institute for Advanced Studies (NIAS to KH and MW). 


\section{NOTE}

1 The managers' age, gender and the industry of their organisation did not significantly influence the dependent variable or moderate other effects, and are therefore not included in the models presented here.

\section{References}

Adler, G. and Hilber, D. 20og. Industry hiring patterns of older workers. Research on Aging, 31, 1, 69-88.

Ahmed, A. M., Andersson, L. and Hammarstedt, M. 2012. Does age matter for employability? A field experiment on ageism in the Swedish labour market. Applied Economic Letters, 19, 4, 403-6.

Akerlof, G. A. 1970. The market for 'lemons': quality uncertainty and the market mechanism. The Quarterly Journal of Economics, 84, 3, 488-500.

Bal, A. C., Reiss, A. E. B., Rudolph, C. W. and Baltes, B. B. 2011 . Examining positive and negative perceptions of older workers: a meta-analysis. Journals of Gerontology: Psychological Sciences and Social Sciences, 66B, 6, 687-98.

Bangerter, A., Roulin, N. and König, C.J. 2012. Personnel selection as a signaling game. Journal of Applied Psychology, 97, 4, 719-38.

Barker, V.L. and Mone, M.A. 1998. The mechanistic structure shift and strategic reorientation in declining firms attempting turnarounds. Human Relations, 51, $10,1227-5^{8}$.

Baxter, J. C., Brock, B., Hill, P. C. and Rozelle, R. M. 1981. Letters of recommendation: a question of value. Journal of Applied Psychology, 66, 3, 296-301.

Beck, V. 2013 . Employers' use of older workers in the recession. Employee Relations, $35,3,257-71$.

Becker, G. 1975. Human Capital: A Theoretical and Empirical Analysis with Special Reference to Education. National Bureau of Economic Research, New York.

Bendick, M., Brown, L. E. and Wall, K. 1999. No foot in the door: an experimental study of employment discrimination against older workers. Journal of Aging $\mathcal{E}$ Social Policy, 10, 4, 5-23.

Bills, D. B. 1990. Employers' use of job history data for making hiring decisions: a fuller specification of job assignment and status attainment. The Sociological Quarterly, 31, 1, 23-35.

Chan, S. and Stevens, A. H. 2001. Job loss and employment patterns of older workers. Journal of Labor Economics, 19, 2, 484-521.

Chen, C. C., Huang, Y. M. and Lee, M. I. 2011. Test of a model linking applicant résumé information and hiring recommendations. International Journal of Selection and Assessment, 19, 4, 374-87.

Chiu, W. C. K., Chan, A. W., Snape, E. and Redman, T. 2001. Age stereotypes and discriminatory attitudes towards older workers: an East-West comparison. Human Relations, 54, 5, 629-61.

Cole, M. S., Feild, H. S. and Giles, W. F. 2003. What can we uncover about applicants based on their resumes? A field study. Applied HRM Research, 8, 2, 51-62.

Cole, M. S., Feild, H. S., Giles, W. F. and Harris, S. G. 2009. Recruiters' inferences of applicant personality based on resume screening: do paper people have a personality? Journal of Business and Psychology, 24, 1, 5-18.

Cole, M. S., Rubin, R. S., Feild, H. S. and Giles, W. F. 2007. Recruiters' perceptions and use of applicant résumé information: screening the recent graduate. Applied Psychology: An International Review, 56, 2, 314-43. 
D'Addio, A. C., Keese, M. and Whitehouse, E. 2010. Population ageing and labour markets. Oxford Review of Economic Policy, 26, 4, 613-35.

Daniel, K. and Heywood, J. S. 2007. The determinants of hiring older workers: UK evidence. Labour Economics, 14, 1, 35-51.

De Graaf-Zijl, M., Van Der Horst, A., Van Vuuren, D., Erken, H. and Luginbuhl, R. 2015. Long-term unemployment and the Great Recession in the Netherlands: economic mechanisms and policy implications. De Economist, 163, 4, 41 $5^{-34}$.

Demerouti, E., Bakker, A. B., Nachreiner, F. and Schaufeli, W. B. 2001. The job demands-resources model of burnout. Journal of Applied Psychology, 86, 3, 499-512.

Derous, E., Ryan, A. M. and Serlie, A.W. 2015. Double jeopardy upon resumé screening: when Achmed is less employable than Aïsha. Personnel Psychology, 68, 3, 659-96.

Erdogan, B., Bauer, T. N., Peiró, J. M. and Truxillo, D. M. 2011 . Overqualified employees: making the best of a potentially bad situation for individuals and organizations. Industrial and Organizational Psychology, 4, 2, $215^{-32 .}$

Finkelstein, L. M., Burke, M. J. and Raju, N. S. 1995. Age discrimination in simulated employment contexts: an integrative analysis. Journal of Applied Psychology, 8o, 6, $65^{2-63}$.

Finkelstein, L. M., King, E. B. and Voyles, E. C. 2015. Age metastereotyping and cross-age workplace interactions: a meta view of age stereotypes at work. Work, Aging and Retirement, 1, 1, 26-40.

Gordon, R. A., Rozelle, R. M. and Baxter, J. C. 1988. The effect of applicant age, job level, and accountability on the evaluation of job applicants. Organizational Behaviour and Human Decision Processes, 41, 1, 22-33.

Hainmueller, J., Hangartner, D. and Yamamoto, T. 2015. Validating vignette and conjoint survey experiments against real-world behavior. Proceedings of the National Academy of Sciences of the United States of America, 1 12, 8, 2395-400.

Huang, Y. M., Chen, C .C. and Lai, S. Y. 2013. Test of a multidimensional model linking applicant work experience and recruiters' inferences about applicant competencies. International Journal of Human Resource Management, 24, 19, 3613-29.

Jackson, S. E. and Schuler, R. S. 1995. Understanding human resource management in the context of organizations and their environments. Annual Review of Psychology, 46, 237-64.

Karasek, R., Brisson, C., Kawakami, N., Houtman, I., Bongers, P. and Amick, B. 1998. The Job Content Questionnaire (JCQ): an instrument for internationally comparative assessments of psychosocial job characteristics. Journal of Occupational Health Psychology, 3, 4, 322-55.

Karpinska, K., Henkens, K. and Schippers, J. 2013. Retention of older workers: impact of managers' age norms and stereotypes. European Sociological Review, 29, $6,1323-35$.

Karren, R. and Sherman, K. 2012 . Layoffs and unemployment discrimination: a new stigma. Journal of Managerial Psychology, 27, 8, 848-63.

Kim, Y. and Ployhart, R. E. 2014. The effects of staffing and training on firm productivity and profit growth before, during, and after the Great Recession. Journal of Applied Psychology, 99, 3, 361-89.

Kristof-Brown, A. L., Zimmerman, R. D. and Johnson, E. C. 2005. Consequences of individuals' fit at work: a meta-analysis of person-job, person-organization, person-group, and person-supervisor fit. Personnel Psychology, 58, 2, 281-342.

Kunze, F., Boehm, S. and Bruch, H. 2013. Age, resistance to change, and job performance. Journal of Managerial Psychology, 28, 7/8, 741-6o. 
Landy, F. J. 2008. Stereotypes, bias, and personnel decisions: strange and stranger. Industrial and Organizational Psychology, 1, 4, 379-92.

Latham, S. F. and Braun, M. R. 2011. Economic recessions, strategy, and performance: a synthesis. Journal of Strategy and Management, 4, 2, 96-115.

Lockwood, B. 1991. Information externalities in the labour market and the duration of unemployment. Review of Economic Studies, 58, 4, 733-53.

Marsden, P. V. and Gorman, E. H. 2001. Social networks, job changes, and recruitment. In Berg, I. E. and Kalleberg, A. L. (eds), Sourcebook of Labor Markets: Evolving Structures and Processes. Plenum Press, New York, 476-502.

Martinez, P. G., Lengnick-Hall, M. L. and Kulkarni, M. 2014. Overqualified? A conceptual model of managers' perceptions of overqualification in selection decisions. Personnel Review, 43, 6, 957-74.

Morgeson, F. P. and Campion, M. A. 1997. Social and cognitive sources of potential inaccuracy in job analysis. Journal of Applied Psychology, 82, 5, 627-55.

Muchinsky, P. M. 1979. The use of reference reports in personnel selection: a review and evaluation. Journal of Occupational Psychology, 52, 4, 287-97.

Neumark, D. and Button, P. 2014. Did age discrimination protection help older workers weather the Great Recession? Journal of Policy Analysis and Management, 33, 3, 566-6o1.

Organisation for Economic Co-operation and Development 2014. Ageing and Employment Policies: Netherlands 2014: Working Better with Age. OECD Publishing, Paris.

Oude Mulders, J., Henkens, K. and Schippers, J. 2016. European top managers' age-related workplace norms and their organizations' recruitment and retention practices regarding older workers. The Gerontologist. Published online 21 April. doi: $10.1093 /$ geront/gnwo 76 .

Oude Mulders, J., Van Dalen, H. P., Henkens, K. and Schippers, J. 2014 . How likely are employers to rehire older workers after mandatory retirement? A vignette study among managers. De Economist, 162, 4, 41 $5^{-31}$.

Pager, D. and Quillian, L. 2005. Walking the talk? What employers say versus what they do. American Sociological Review, 7o, 3, 355-80.

Perry, E. L., Golom, F. D., Catenacci, L., Ingraham, M. E., Covais, E. M. and Molina, J.J. 2016. Talkin' 'bout your generation: the impact of applicant age and generation on hiring-related perceptions and outcomes. Work, Aging and Retirement. Published online 11 October. doi: 10.1093/workar/wawo29.

Posthuma, R.A. and Campion, M.A. 2009. Age stereotypes in the workplace: common stereotypes, moderators, and future research directions. Journal of Management, 35, 1, $15^{8-88 .}$

Protsch, P. and Solga, H. 2015 . How employers use signals of cognitive and noncognitive skills at labour market entry. Insights from field experiments. European Sociological Review, 31, 5, $5^{21-32 .}$

Robie, C., Emmons, T., Tuzinski, K. A. and Kantrowitz, T. 2011 . Effects of an economic recession on leader personality and general mental ability scores. International Journal of Selection and Assessment, 19, 2, 183-9.

Roscigno, V.J., Mong, S., Byron, R. and Tester, G. 2007. Age discrimination, social closure and employment. Social Forces, 86, 1, 313-34.

Rosen, B. and Jerdee, T. H. 1976. The influence of age stereotypes on managerial decisions. Journal of Applied Psychology, 61, 4, 428-32.

Rossi, P. H. and Anderson, A. B. 1982. The factorial survey approach: an introduction. In Rossi, P. H. and Nock, S. L. (eds), Measuring Social Judgments: The Factorial Survey Approach. Sage, Beverly Hills, California, $15^{-67 .}$ 


\section{Jaap Oude Mulders et al.}

Schaufeli, W. B., Bakker, A. B. and Van Rhenen, W. 2009. How changes in job demands and resources predict burnout, work engagement, and sickness absenteeism. Journal of Organizational Behavior, 3o, 7, 893-91 7 .

Scherpenzeel, A. C. and Das, M. 2010. 'True' longitudinal and probability-based internet panels: evidence from the Netherlands. In Das, M., Ester, P. and Kaczmirek, L. (eds), Social and Behavioral Research and the Internet: Advances in Applied Methods and Research Strategies. Taylor \& Francis, Boca Raton, Florida, 77-104.

Schmidt, F. L. and Zimmerman, R. D. 2004. A counterintuitive hypothesis about employment interview validity and some supporting evidence. Journal of Applied Psychology, 89, 3, 553-61.

Snijders, T. A. B. and Bosker, R. J. 1999. Multilevel Analysis: An Introduction to Basic and Advanced Multilevel Modeling. Sage, London.

Spence, M. 1973. Job market signaling. The Quarterly Journal of Economics, 87, 3, $355^{-74}$.

Tourangeau, R., Rasinski, K. A., Bradburn, N. and D’Andrade, R. 1989. Carryover effects in attitude surveys. Public Opinion Quarterly, 53, 4, 495-524.

Tsai, W. C., Chi, N. W., Huang, T. C. and Hsu, A.J. 2011. The effects of applicant résumé contents on recruiters' hiring recommendations: the mediating roles of recruiter fit perceptions. Applied Psychology: An International Review, 6o, 2, 231-54.

Van Dalen, H. P. and Henkens, K. 2013. Dilemmas of downsizing during the Great Recession: crisis strategies of European employers. De Economist, 161, 3, 307-29.

Van Dalen, H. P., Henkens, K. and Schippers, J. 2010. Productivity of older workers: perceptions of employers and employees. Population and Development Review, 36, 2, 309-30.

Wald, S. 2005. The impact of overqualification on job search. International Journal of Manpower, 26, 2, $14^{0}-5^{6}$.

Wallander, L. 2009. 25 years of factorial surveys in sociology: a review. Social Science Research, 38, 3, 50 $5^{-20 .}$

Wanberg, C. R., Kanfer, R., Hamann, D. J. and Zhang, Z. 2016. Age and reemployment success after job loss: an integrative model and meta-analysis. Psychological Bulletin, 142, 4, 400-26.

Wang, M., Olson, D. and Shultz, K. 2013. Mid and Late Career Issues: An Integrative Perspective. Psychology Press, New York.

Wheaton, F. and Crimmins, E. M. 2013. The demography of aging and retirement. In Wang, M. (ed.), The Oxford Handbook of Retirement. Oxford University Press, Oxford, 22-41.

Accepted Io November 2016; first published online 2 I December 2 I I 6

Address for correspondence:

Jaap Oude Mulders,

Netherlands Interdisciplinary Demographic Institute,

Lange Houtstraat 19, $25^{11} \mathrm{CV}$,

The Hague, The Netherlands

E-mail: oudemulders@nidi.nl 